\title{
Quercetin attenuates oxidative stress in the blood plasma of rats bearing DMBA-induced mammary cancer and treated with a combination of doxorubicin and docetaxel
}

\author{
Sabina Tabaczar ${ }^{1}$, Anna Pieniążek ${ }^{2}$, Jan Czepas ${ }^{1}$, Joanna Piasecka-Zelga ${ }^{3}$, Krzysztof \\ Gwoździński ${ }^{1}$ and Aneta Koceva-Chyła ${ }^{2}$ \\ ${ }^{1}$ Department of Molecular Biophysics, Faculty of Biology and Environmental Protection, University of Łódź, Łódź, \\ Poland \\ ${ }^{2}$ Department of Thermobiology, Faculty of Biology and Environmental Protection, University of Łódź, Łódź, Poland \\ ${ }^{3}$ Nofer Institute of Occupational Medicine, Łódź, Poland
}

\begin{abstract}
The development of side-effects during doxorubicin-docetaxel (DOX-DTX) chemotherapy is considered as related to generation of oxidative stress by DOX. The addition of docetaxel potentiates this effect. Thus, antioxidants are assumed as a promising remedy for neutralizing deteriorating effects of reactive oxygen species (ROS) in pathological conditions and polyphenolic antioxidants are suitable candidates for such a therapeutic approach.

We evaluated the ability of quercetin to attenuate oxidative stress developed during the process of DMBA carcinogenesis and DOX-DTX chemotherapy in the blood plasma of rats bearing mammary tumors. We have found that quercetin significantly improved the plasma nonenzymatic antioxidant capacity (NEAC) and reduced lipid peroxidation, which suggest the beneficial effect of flavonoid. The inclusion of quercetin to the DOX-DTX chemotherapy was also advantageous. A considerable decrease of carbonyls and lipid peroxidation products (TBARS) and improvement of the endogenous antioxidant defense system (an increase of NEAC, thiols and SOD activity) were observed compared to rats treated with DOX-DTX chemotherapy. These results suggest that quercetin could protect blood plasma constituents against oxidative damage evoked by DOX and DTX.
\end{abstract}

Key words: Flavonoid - Quercetin - Doxorubicin - Docetaxel - Chemotherapy - Oxidative stress

Abbreviations: DOX, doxorubicin; DTX, docetaxel; DMBA, 7,12-dimethylbenz(a)anthracene; FOX, ferric-xylenol orange; NEAC, non-enzymatic antioxidant capacity; ROS, reactive oxygen species; SOD, superoxide dismutase; TBARS, thiobarbituric acid-reactive substances.

\section{Introduction}

Doxorubicin (DOX) and docetaxel (DTX) are among the most efficient anticancer chemotherapeutics and are often used in combination, especially against advanced, refrac-

Correspondence to: Sabina Tabaczar, Department of Molecular Biophysics, Faculty of Biology and Environmental Protection, University of Łódź, Łódź, Poland

E-mail: s.tabaczar@gmail.com tory or metastatic breast cancer. DOX acts via numerous distinct mechanisms and pathways, including intercalation to DNA, induction of apoptosis and direct or indirect production of oxygen free radicals (Koceva-Chyła et al. 2005; Rogalska et al. 2008; Sawyer et al. 2010). Despite the high anticancer efficiency of this anthracycline, its use is often limited due to the systemic and organ toxic effects (mainly cardiotoxicity), which can be developed many years after completion of chemotherapy (Santin et al. 2007). So far, the main mode of the antiproliferative activity of DTX 
(formation of stable microtubules and induction of apoptosis) has focused the most research on this taxane (Morse et al. 2005). More recently, the attention was shifted to the possibility of induction of ROS production by this drug (Mir et al. 2009).

Although the combination of DOX and DTX improves clinical outcome, the addition of taxane enhances the cardiotoxicity of DOX, mainly due to the stimulation of doxorubicinol and the intensified ROS formation in the heart myocytes (Minotti et al. 2001; Salvatorelli et al. 2006). Thus, there is a continuous search for efficient antioxidant compounds, which could suppress the development of oxidative stress and ensure tissue protection against toxicities caused by anthracycline chemotherapy.

Flavonoids are good candidates in this field as they can scavenge different ROS, chelate metal ions and inhibit the activities of some enzymes e.g. NADPH oxidases (Mira et al. 2002; Steffen et al. 2008). The beneficial antioxidant properties of these compounds are still appreciated and several phenolic compounds have been introduced to pre- or clinical trials, e.g. curcumin (Hatcher et al. 2008) and quercetin (Ferry et al. 1996; Jin et al. 2010). Activity of flavonoids in vivo remains, however, not fully revealed, due to their poor solubility and absorption from the gastrointestinal tract and complexity of cellular action. Although flavonoids may prevent tissues and organs from oxidative injury induced by anticancer drugs in vivo, they are double-edged swords and can also act as prooxidants (Lee-Hilz et al. 2006). Furthermore, flavonoids possess pro-apoptotic and anticancer activities and thus could enhance the cytotoxicity of anticancer drugs against tumor cells (Choi et al. 2008).

Quercetin is an essential polyphenolic compound of a diet rich in fruit and vegetables (Slimestad et al. 2007). This flavonoid has been shown to protect against cancer development (Murakami et al. 2008) and oxidative damage generated by DOX in neonatal rat cardiomyocytes (Psotová et al. 2004). In clinical trials i.v. infusions of quercetin did not cause substantial toxicity in humans and adverse effects were observed only for the high doses of flavonoid (Ferry et al. 1996).

Although there are numerous studies on the activity of quercetin in in vivo and in vitro models, the possible protective effect of flavonoid against oxidative damage of blood plasma constituents by process of carcinogenesis and DOX-DTX chemotherapy has not been investigated. To the best of our knowledge our study is the very first one in this field. We employed the animal model of carcinogenesis (Sprague-Dawley rats bearing DMBA-induced mammary tumors) and measured the level of the main biomarkers of oxidative stress in the blood plasma of rats treated with: i) quercetin alone; ii) the combination of DOX and DTX without quercetin and iii) the combination of DOX and DTX with addition of quercetin.

\section{Materials and Methods}

\section{Chemicals}

Quercetin dihydrate was purchased from Carl Roth Gmbh, Germany. DTX and DOX were provided by Sequoia Research Products Ltd., United Kingdom. 2,6-di-tert-butyl4-hydroxytoluene (BHT), 7,12-dimethylbenz(a)anthracene (DMBA), ferrous ammonium sulfate, bovine serum albumin (BSA), 2,4-dinitrophenylhydrazine (DNPH), di-thionitrobenzoic acid (DTNB), 1,1-diphenyl-2-picrylhydrazyl $(\mathrm{DPPH})$, guanidine- $\mathrm{HCl}$ and $\mathrm{D}$-sorbitol were obtained from Sigma-Aldrich. Xylenol orange and adrenaline were purchased from MP Biomedicals. Hydrogen peroxide, 2-thiobarbituric acid (TBA), trichloroacetic acid (TCA), ethylenediaminetetraacetic acid (EDTA) and sodium dodecyl sulfate (SDS) were provided by POCH, Poland. All other reagents were of the highest purity available. Deionized water was used in the preparation of all solutions (Millipore Corp.).

\section{Animal study}

\section{Animals}

The female Sprague-Dawley rats of average weight of $180 \mathrm{~g}$ were housed with free access to water and fed on a standard diet. The experiments were conducted accordingly to the Guide for the Care and Use of Laboratory Animals (National Academic Press, Washington, DC, Ed.7, 1996), and to the guidelines for the Use of Experimental Animals (L358-86/609/EEC) and the Guiding Principles in the Use of Animals in Toxicology (1989). Approval of an appropriate local ethics committee was obtained prior to experiments.

\section{Tumor induction}

Rats were randomly divided into two groups - a control (A) and an experimental (B). The experimental group received intragastrically $20 \mathrm{mg}$ of DMBA in $1 \mathrm{ml}$ of olive oil as described elsewhere (Barros et al. 2004), while the control group received a vehicle only. Rats of the experimental group were examined for tumors weekly. Animals without any sign of tumor induction were removed from the subsequent experiments.

\section{Chemotherapy}

Rats of group B, which developed tumors were divided into 4 subgroups ( 6 animals each). The rats received investigated compounds ten weeks after tumor induction according to the following scheme: 
Group 1: placebo (5\% glucose, a vehicle for anticancer drugs and flavonoid). Rats of this group were marked as untreated

Group 2: $10 \mathrm{mg}$ quercetin

Group 3: $5 \mathrm{mg}$ DOX followed by 7.5 mg DTX injected one hour later

Group 4: $5 \mathrm{mg}$ DOX and $10 \mathrm{mg}$ quercetin followed by $7.5 \mathrm{mg}$ DTX one hour later

The above amounts of all compounds were calculated per $\mathrm{kg}$ b.w., suspended in 5\% glucose and administered i.p. 3 times at 3-week intervals.

DOX and DTX doses were calculated in relation to the corresponding doses used in human breast cancer therapy (Misset et al. 1999; Nabholtz 2003; Reagan-Shaw et al. 2007). In our previous study, the dose of $10 \mathrm{mg} \mathrm{DOX} / \mathrm{kg}$ b.w. was applied to show protective properties of nitroxyl antioxidants on heart myocytes in vivo (Koceva-Chyla et al. 2003).

Quercetin dose, evaluated in the pilot experiment and selected as the most optimal on the basis of general toxicity (e.g. weight loss, data not shown) is consistent with the previous data for this flavonoid in humans (Ferry et al. 1996). It has been also shown that the combination of equal doses of DTX and DOX increased general toxicity, but did not enhance substantially alterations in cardiac function caused by DOX employed as a single drug (Platel et al. 2000).

\section{Preparation of plasma samples}

The rats were anesthetized, and blood from femoral vein was collected on EDTA four days after the last course of chemotherapy. Plasma was separated by centrifugation at $1500 \times g$ for $10 \mathrm{~min}$ and fresh samples were used for further analyses. Each sample was analyzed at least in triplicate.

\section{Biochemical assays}

\section{Thiol groups}

The total amount of thiol groups $(-\mathrm{SH})$ was measured spectrophotometrically at $412 \mathrm{~nm}$ as described previously (Ellman 1959). $100 \mu \mathrm{l}$ of $10 \%$ SDS was added to an equal volume of blood plasma, mixed with $10 \mathrm{mM}$ phosphate buffer $(\mathrm{pH} 8)$ and the absorbance was measured at $412 \mathrm{~nm}$ (A0) against the blank. Subsequently, $100 \mu \mathrm{l}$ of DTNB was added and samples were incubated at $37^{\circ} \mathrm{C}$ for $60 \mathrm{~min}$. After incubation the absorbance was measured again at $412 \mathrm{~nm}$ (A1). Then, A0 was subtracted from A1 and the thiol group concentration was calculated using a molar extinction coefficient of $13.6 \times 10^{3} \mathrm{M}^{-1} \cdot \mathrm{cm}^{-1}$. Results were expressed in nanomoles of thiol groups per $\mathrm{mg}$ of protein.

\section{Protein carbonyl groups}

Protein carbonyl groups were measured using DNPH as described by Levine et al. (2000). Blood plasma samples containing $1 \mathrm{mg}$ of protein were mixed with $1 \mathrm{ml}$ of a $10 \mathrm{mM}$ DNPH in $2.5 \mathrm{M} \mathrm{HCl}$ and incubated for $1 \mathrm{~h}$ at room temperature, in the dark. During incubation the samples were stirred every $15 \mathrm{~min}$. After incubation, $1 \mathrm{ml}$ of $20 \%$ trichloroacetic acid was added, samples were left to precipitate on ice for 10 min and then centrifuged $(3000 \times g, 10 \mathrm{~min}$, room temperature). The protein pellet after three washings with ethanol: ethyl acetate solution $(1: 1 \mathrm{ratio}, \mathrm{v} / \mathrm{v})$ was suspended in $1 \mathrm{ml}$ of $6 \mathrm{M}$ guanidine- $\mathrm{HCl}$ and incubated at $37^{\circ} \mathrm{C}$ for $30 \mathrm{~min}$. The absorbance was read at $370 \mathrm{~nm}$ against blank (6 M guanidine- $\mathrm{HCl}$ ). The carbonyl groups' content was calculated from molar absorption coefficient $\varepsilon=21 \times 10^{3} \mathrm{M}^{-1} \cdot \mathrm{cm}^{-1}$ and expressed in nanomoles per $\mathrm{mg}$ of protein.

\section{Hydroperoxides}

The FOX 1 method was used for determination of hydroperoxide content (Gay and Gebicki 2000). $100 \mu \mathrm{l}$ of blood plasma was mixed with $1 \mathrm{ml}$ of working FOX 1 reagent (solution of $125 \mu \mathrm{M}$ xylenol orange and $100 \mathrm{mM}$ sorbitol in $25 \mathrm{mM} \mathrm{H}_{2} \mathrm{SO}_{4}$, prepared each time before the use by the addition of ammonium ferrous sulfate to the final $250 \mu \mathrm{M}$ concentration), vortexed, centrifuged $\left(20^{\circ} \mathrm{C}, 3000 \times g, 10\right.$ $\mathrm{min}$ ) and incubated at room temperature, in the dark, for 30 min. After incubation, the absorbance of supernatant was read at $560 \mathrm{~nm}$ against the blank. Hydroperoxide amount was calculated from a standard curve for $\mathrm{H}_{2} \mathrm{O}_{2}$.

\section{Thiobarbituric acid-reactive substances (TBARS)}

The amount of thiobarbituric acid-reactive substances was measured by the method described by Rice-Evans et al. (Rice-Evans et al. 1991). Blood plasma was mixed with equal volumes of $15 \%(\mathrm{w} / \mathrm{v})$ trichloroacetic acid in $0.25 \mathrm{M} \mathrm{HCl}$ and $0.37 \%(\mathrm{w} / \mathrm{v}) 2$-thiobarbituric acid in $0.25 \mathrm{M} \mathrm{HCl}$, containing $2 \% \mathrm{BHT}$, and incubated at $100^{\circ} \mathrm{C}$ for $10 \mathrm{~min}$. After then, the samples were cooled on ice and centrifuged $(3000 \times g, 5 \mathrm{~min}$, $20^{\circ} \mathrm{C}$ ). The supernatant was collected and its absorbance measured at $535 \mathrm{~nm}$ against the blank. TBARS content was calculated from $\mathrm{E}=1.56 \times 10^{5} \mathrm{M}^{-1} \cdot \mathrm{cm}^{-1}$ and expressed in nanomoles of TBARS per milligram of protein.

\section{SOD activity}

The indirect adrenaline assay based on the measurement of inhibition of adrenaline autooxidation at $480 \mathrm{~nm}$ was used to calculate SOD activity (Misra and Fridovich 1972). The plasma sample which caused 50\% inhibition of adrenaline autooxidation was regarded as containing one unit of SOD. 
The enzyme activity was expressed in international units per milligram of protein.

\section{Plasma non-enzymatic antioxidant capacity (NEAC)}

The estimation of the non enzymatic antioxidant capacity of the blood plasma was performed using 1,1-diphenyl2-picrylhydrazyl (DPPH) reduction assay according to Yamaguchi et al. (1998) with some modifications. $20 \mu \mathrm{l}$ of blood plasma was mixed with $400 \mu \mathrm{l}$ of a $0.1 \mathrm{mM}$ methanol solution of DPPH. Following $30 \mathrm{~min}$ incubation at room temperature and centrifugation $(10 \mathrm{~min}, 3000 \times \mathrm{g})$ the absorbance was measured at $517 \mathrm{~nm}$. The antioxidant capacity of the plasma was expressed in nmol Trolox equivalents per mg of protein.

\section{Assessment of protein content}

The protein concentration in each sample was measured by the Lowry method from the standard curve for BSA (Lowry 1951).

\section{Statistical Analysis}

Shapiro-Wilk's test was used to evaluate the normal distribution of data. Homogeneity of variance was evaluated by the Levene's test. Student's $t$ - test was applied in order to estimate the statistical significance between the groups (Table 1). The parametric, two-way analysis of variance was used to test any possible interactions between compounds (DOX-DTX and quercetin). The two-way nested analysis of variance was used in the case of interactions, assuming that the effect of drugs is at a higher level of importance than the effect of quercetin (Sokal and Rohlf 1994; Zar 1999). Differences were considered significant at $p<0.05$.

The Statistica (StatSoft Inc., Tulsa, OK, USA) and StatsDirect (StatsDirect Ltd., England) software was used for all calculations.

\section{Results}

\section{Changes in the blood plasma of untreated tumor-bearing rats}

Alterations in the amount of analyzed biomarkers of oxidative stress in the blood plasma of healthy (control) and tumor-bearing rats (untreated) provided in Table 1 imply that the process of DMBA-carcinogenesis generates significant oxidative stress in the tumor-bearing rats. This is evidenced by an increase in protein carbonyls and lipid peroxidation products (hydroperoxides and TBARS) and a decrease in SOD activity. Additionally, an increase in the non-enzymatic antioxidant capacity (NEAC) and thiol groups has also been observed.

\section{The effect of quercetin}

Administration of quercetin caused a decrease of lipid peroxidation products (TBARS and hydroperoxides) in the blood plasma of tumor-bearing rats but did not influence protein carbonyl groups and SOD activity. The flavonoid also reduced the content of thiol groups to the level of the control animals and evoked an increase of the NEAC (Table 1).

The impact of quercetin on the oxidative stress generated by DOX and DTX

The inclusion of quercetin into DOX-DTX chemotherapy effectively protected the blood plasma constituents against oxidative damage induced by these drugs and resulted in a decrease in lipid peroxidation end products (TBARS) and protein carbonyl groups. Moreover, the addition of flavonoid increased the amount of thiols, non-enzymatic plasma antioxidant capacity (NEAC) and SOD activity but also the level of hydroperoxides (Figure 1). Quercetin had the positive effect on the outcome of chemotherapy as greater reduction in tumor size was observed in rats treated with

Table 1. The impact of quercetin on the main biomarkers of oxidative stress in the blood plasma of Sprague-Dawley rats bearing DMBA-induced mammary tumors

\begin{tabular}{|c|c|c|c|c|c|c|c|}
\hline Group & & $\begin{array}{c}\text { Thiol groups } \\
\text { (nmol/mg } \\
\text { protein) }\end{array}$ & $\begin{array}{c}\text { Carbonyl groups } \\
\text { (nmol/mg } \\
\text { protein) }\end{array}$ & $\begin{array}{l}\text { Hydroperoxides } \\
\text { (nmol/mg } \\
\text { protein) }\end{array}$ & $\begin{array}{l}\text { TBARS } \\
\text { (nmol/mg } \\
\text { protein) }\end{array}$ & $\begin{array}{c}\text { SOD } \\
\text { (U/mg protein) }\end{array}$ & $\begin{array}{c}\text { NEAC } \\
(\mathrm{nmol} / \mathrm{mg} \\
\text { protein) }\end{array}$ \\
\hline Contr & & $2.90 \pm 0.523$ & $2.46 \pm 0.407$ & $0.19 \pm 0.045$ & $0.06 \pm 0.004$ & $0.37 \pm 0.059$ & $2.39 \pm 0.892$ \\
\hline \multirow{2}{*}{ DMBA } & Unt & $6.73 \pm 1.432^{\star * *}$ & $3.21 \pm 0.746^{* \star *}$ & $0.43 \pm 0.175^{\star *}$ & $0.09 \pm 0.029^{\star *}$ & $0.29 \pm 0.044^{* *}$ & $9.82 \pm 1.903^{\star * *}$ \\
\hline & Quercetin & $2.68 \pm 1.080^{\# \# \#}$ & $2.74 \pm 0.682^{\text {n.s. }}$ & $0.05 \pm 0.025^{\# \# \#}$ & $0.04 \pm 0.009^{\# \# \#}$ & $0.30 \pm 0.053^{\text {n.s. }}$ & $11.94 \pm 0.752^{\# \#}$ \\
\hline
\end{tabular}

Data were expressed as mean \pm SD. Control, healthy rats; Untreated, rats with tumors receiving placebo only (5\% glucose); Quercetin, quercetin-treated rats; DMBA, -7,12-dimethylbenz(a)anthracene; NEAC, non-enzymatic antioxidant capacity; SOD, superoxide dismutase; TBARS, thiobarbituric acid-reactive substances. ${ }^{* *} p<0.001,{ }^{* * *} p<0.0001-v s$. healthy rats; ${ }^{\# \#} p<0.002,{ }^{\# \# \#} p<0.0001-v s$. untreated rats; n.s., non significant. 

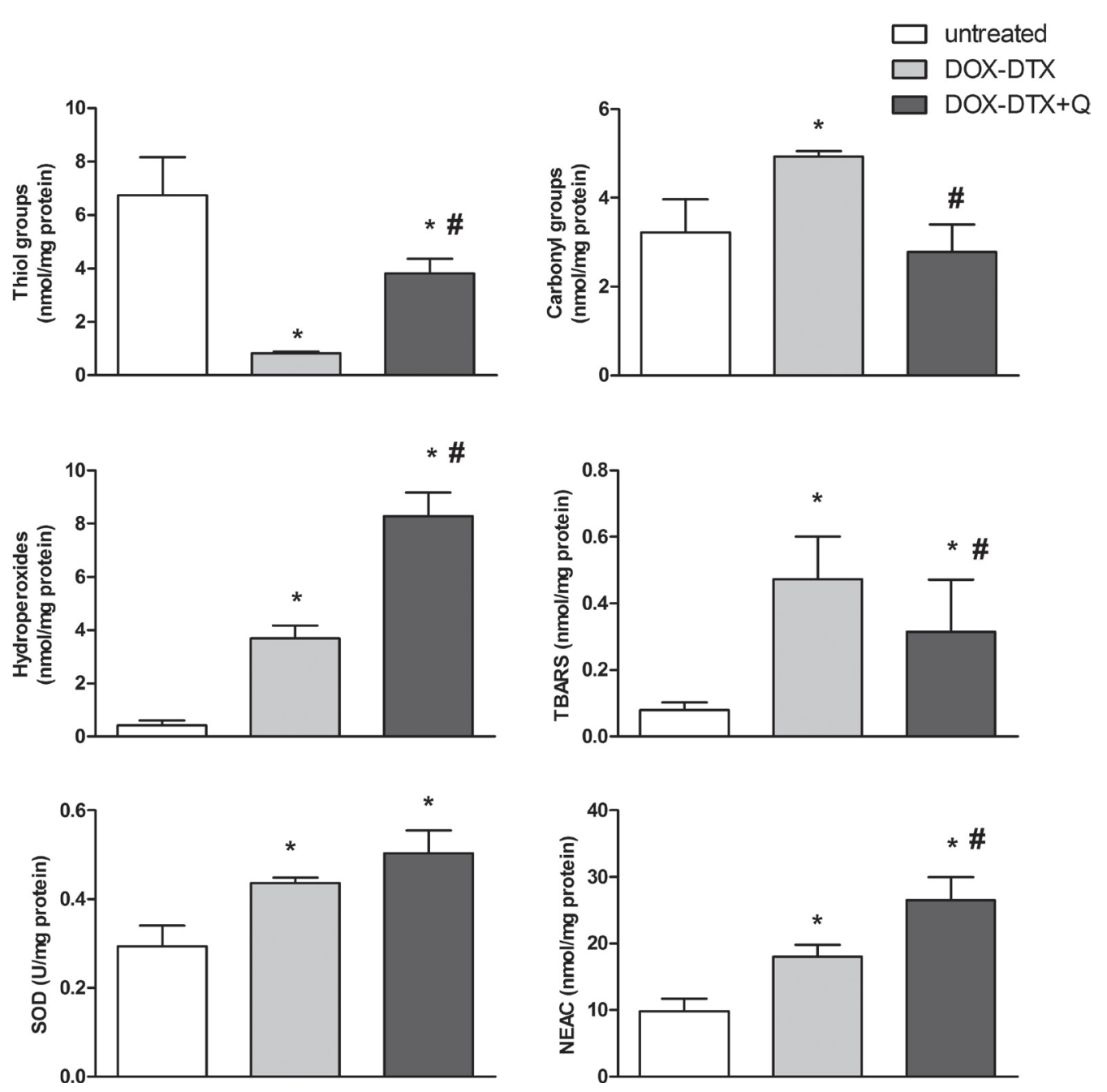

Figure. 1. The effect of quercetin $(\mathrm{Q})$ on the oxidative stress generated by combination of anticancer drugs doxorubicin (DOX) and docetaxel (DTX) in the blood plasma of rats with experimental mammary cancer. Data were expressed as mean \pm SD. ${ }^{*} p<0.05$ denotes a statistically significant difference in relation to untreated rats, $\# p<0.05$ DOX-DTX $v s$. DOX-DTX+Q.

DOX-DTX chemotherapy with the addition of flavonoid (data not shown).

\section{Discussion}

Anticancer drugs induce extensive oxidative stress in both normal and tumor cells. Electrophilic aldehydes, which are end products of lipid peroxidation cause perturbation in the cell cycle progression and arrest of cells in the cycle checkpoints (Ji et al. 1998; Chua et al. 2009). In cancer cells this effect may hamper the anticancer activity of chemotherapeutics and lessen the efficacy of the treatment. Oxidative damage of lipids, proteins and DNA in normal cells can in turn destroy the functions of many tissues, which leads to severe side effects of chemotherapy employing drugs that generate oxidative stress. Moreover, products of lipid peroxidation can also inhibit drug-induced apoptosis through inactivating death receptors and caspase activity (Camandola et al. 2000; Leonarduzzi et al. 2000; Liu et al. 2000; Yang et al. 2003). Thus, the use of antioxidants may enhance the efficacy of chemotherapy and reduce its undesirable nontargeted effects by ameliorating the generation of oxidative stress-induced harmful products, e.g. aldehydes.

Oxidative stress is also inevitably associated with the process of carcinogenesis (Barrera 2012). In untreated tumor-bearing rats we have observed a considerable increase in the level of carbonyl groups, hydroperoxides and TBARS, coupled with a decrease in SOD activity and an increase in thiols and NEAC. This indicates the existence of extensive oxidative stress, linked to the process of DMBA-carcinogenesis and tumor development which is in line with other 
papers showing the significance of oxidative stress in these processes (Kumaraguruparan et al. 2002; Klaunig et al. 2011).

In tumor-bearing rats treated with quercetin a significant decrease in TBARS and hydroperoxides suggests protective effect of flavonoid on peroxidation of the blood plasma lipids. This is in accordance with the earlier report showing a reduction in lipid peroxidation products in the plasma of rats treated with this flavonoid (da Silva et al. 1998). At the same time we did not observe any impact of quercetin on the level of protein carbonylation. Similar effect of flavonoid has been observed by Ameho et al. (2008) in the vitamin Edepleted rats administered with this flavonoid.

Administration of quercetin did not cause any changes in SOD activity. Conversely to our results an increase in SOD activity in mice receiving quercetin has been reported (Kamaraj et al. 2007). It should be mentioned that in these experiments much higher doses of flavonoid were applied ( $25 \mathrm{mg} / \mathrm{kg}$ body weight, twice a week for 16 weeks) which could exert other effect on SOD activity. In addition, quercetin has been shown to suppress activation of pro-inflammatory NF- $\kappa$ B via reducing ROS level (Nam et al. 2006). Flavonoid could also decrease the level of pro-inflammatory tumor necrosis factor (TNF- $\alpha$ ) in blood plasma of mice (Boesch-Saadatmandi et al. 2011) and thus protect against oxidative stress mediated by this cytokine. Other studies indicate that quercetin empowers the endogenous antioxidant system due to upregulation of the antioxidant enzyme activity (Kamaraj et al. 2007; Bournival et al. 2012; Huang et al. 2012). Moreover, it has been also suggested that flavonoids might act synergistically with the endogenous antioxidant system and thus decrease oxidative stress (Chen et al. 2005).

In our experimental setting quercetin also caused augmentation of NEAC in tumor-bearing rats. This suggests the ability of low molecular weight antioxidants of blood plasma to sustain its proper redox state in conditions of oxidative stress. Recently, quercetin has been shown to increase the level of heme oxygenase 1 protein (HO-1), probably via an Nrf2-dependent pathway (Boesch-Saadatmandi et al. 2011), which consecutively may increase the level of bilirubin (Zelenka et al. 2012). This mechanism somewhat could also contribute to a rise of NEAC observed in our study. In turn, the reduction of thiols in the tumor-bearing rats to the level of control animals might be due to the formation of quercetin conjugates with -SH groups as it has been suggested by other authors (Jacobs et al. 2010).

We examined antioxidant properties of quercetin and its protective effects on the damage to the blood plasma constituents by oxidative stress generated by DOX-DTX chemotherapy. So far, this aspect of quercetin activity has not been investigated in vivo. Different studies report on the ability of antineoplastic agents to generate ROS in biological systems (Minotti et al. 2001; Mir et al. 2009; Sawyer et al. 2010). Thus, the abrogation of chemotherapy-related damage by redox modulation with the use of quercetin, might have potential beneficial therapeutic implications. It should be mentioned that new clinical trials with employment of this flavonoid have been running for the last two years: A phase 1 study of quercetin in patients with Hepatitis C (National Institute of Diabetes and Digestive and Kidney Diseases, NIDDK, University of California, Los Angeles); and Clinical trial on the effectiveness of the flavonoids genistein and quercetin in men with rising prostate-specific antigen (Institute of Nutritional Medicine, University of Hohenheim, Stuttgart, Germany; University of Hohenheim).

Addition of quercetin to DOX-DTX chemotherapy in our study had positive impact on the plasma proteins and effectively shielded plasma lipids against oxidative destruction caused by DOX and DTX treatment. A decreased level of protein carbonylation and the end products of lipid peroxidation in plasma of rats receiving combination of drugs with quercetin was observed in comparison to the treatment with the anticancer drugs only. Several in vitro and in vivo reports describe quercetin ability to protect lipids against peroxidation (da Silva et al. 1998; Mahesh and Menon 2004; Gargouri et al. 2011). This effect of flavonoid could be related to its iron-chelation properties. Some evidence points out that accessibility of iron is a key factor in oxygen radical-mediated lipid peroxidation (Fischer et al. 2002).

In contrast to the attenuation of the TBARS production, the inclusion of quercetin into DOX and DTX treatment enhanced hydroperoxide production, which could suggest prooxidant activity of flavonoid. Other authors showed that under specific conditions quercetin may exhibit prooxidant activity by increasing hydroperoxide production (Rolewski et al. 2009). It should be mentioned that hydroperoxides, in contrast to TBARS, are unstable products of the earlier stages of lipid peroxidation and may be successfully restored. Thus, we consider the arrest of lipid peroxidation in its earlier stages as a protective effect of quercetin, which on one side causes an increase in hydroperoxides but on the other side leads to a decrease in the amount of the most harmful and irreversible end-products of lipid peroxidation such as aldehydes. Effective protection of plasma constituents against DOX-DTX chemotherapy-induced oxidative damage confirms antioxidative properties of quercetin in vivo and is in line with reports showing the preventive role of this flavonoid against oxidation of erythrocyte and lymphocyte proteins (Pandey and Rizvi 2010; Gargouri et al. 2011).

Summarizing, our investigation shows that quercetin is able to protect proteins and lipids of blood plasma of tumorbearing rats against oxidative damage caused by combined DOX-DTX chemotherapy and shield nontargeted tissue against toxicity of these anticancer drugs. 
All authors have no conflict of interest to disclose.

Acknowledgement. The work described in this paper was supported by a grant from the Ministry of Science and Higher Education (Poland) N 4012337 33. S. Tabaczar would like to acknowledge a D-RIM fellowship co-funded by the European Social Fund: "HUMAN - BEST INVESTMENT".

\section{References}

Ameho C. K., Chen C. Y., Smith D., Sánchez-Moreno C., Milbury P. E., Blumberg J. B. (2008): Antioxidant activity and metabolite profile of quercetin in vitamin-E-depleted rats. J. Nutr. Biochem. 19, 467-474

http://dx.doi.org/10.1016/j.jnutbio.2007.06.004

Barrera G. (2012): Oxidative stress and lipid peroxidation products in cancer progression and therapy. ISRN Oncol. 2012, 137289

Barros A. C., Muranaka E. N., Mori L. J., Pelizon C. H., Iriya K., Giocondo G., Pinotti J. A. (2004): Induction of experimental mammary carcinogenesis in rats with 7,12-dimethylbenz(a)an thracene. Rev. Hosp. Clin. Fac. Med. S. Paulo. 59, 257-261 http://dx.doi.org/10.1590/S0041-87812004000500006

Boesch-Saadatmandi C., Loboda A., Wagner A. E., Stachurska A., Jozkowicz A., Dulak J., Döring F., Wolffram S., Rimbach G. (2011): Effect of quercetin and its metabolites isorhamnetin and quercetin-3-glucuronide on inflammatory gene expression: role of miR-155. J. Nutr. Biochem. 22, 293-299 http://dx.doi.org/10.1016/j.jnutbio.2010.02.008

Bournival J., Francoeur M.-A., Renaud J., Martinoli M.-G. (2012): Quercetin and sesamin protect neuronal PC12 cells from highglucose-induced oxidation, nitrosative stress, and apoptosis. Rejuvenation Res. 15, 322-333 http://dx.doi.org/10.1089/rej.2011.1242

Camandola S., Poli G., Mattson M. P. (2000): The lipid peroxidation product 4-hydroxy-2,3-nonenal increases AP-1-binding activity through caspase activation in neurons. J. Neurochem. 74, 159-168 http://dx.doi.org/10.1046/j.1471-4159.2000.0740159.x

Chen C. Y., Milbury P. E., Lapsley K., Blumberg J. B. (2005): Flavonoids from almond skins are bioavailable and act synergistically with vitamins $\mathrm{C}$ and $\mathrm{E}$ to enhance hamster and human $\mathrm{LDL}$ resistance to oxidation. J. Nutr. 135, 1366-1373

Choi E. J., Bae S. M., Ahn W. S. (2008): Antiproliferative effects of quercetin through cell cycle arrest and apoptosis in human breast cancer MDA-MB-453 cells. Arch. Pharm. Res. 31, $1281-1285$ http://dx.doi.org/10.1007/s12272-001-2107-0

Chua P.-J., Yip G. W.-C., Bay B.-H. (2009): Cell cycle arrest induced by hydrogen peroxide is associated with modulation of oxidative stress related genes in breast cancer cells. Exp. Biol. Med. 234, 1086-1094 http://dx.doi.org/10.3181/0903-RM-98

da Silva E. L., Piskula M. K., Yamamoto N., Moon J. H., Terao J. (1998): Quercetin metabolites inhibit copper ion-induced lipid peroxidation in rat plasma. FEBS Lett. 430, 405-408 http://dx.doi.org/10.1016/S0014-5793(98)00709-1
Ellman G. L. (1959): Tissue sulfhydryl groups. Arch. Biochem. Biophys. 82, 70-77 http://dx.doi.org/10.1016/0003-9861(59)90090-6

Ferry D. R., Smith A., Malkhandi J., Fyfe D. W., deTakats P. G., Anderson D., Baker J., Kerr D. J. (1996). Phase I clinical trial of the flavonoid quercetin: Pharmacokinetics and evidence for in vivo tyrosine kinase inhibition. Clin. Cancer Res. 2, 659-668

Fischer J. G., Glauert H. P., Yin T., Sweeney-Reeves M. L., Larmonier N., Black M. C. (2002): Moderate iron overload enhances lipid peroxidation in livers of rats, but does not affect NF-kappaB activation induced by the peroxisome proliferator, Wy-14,643. J. Nutr. 132, 2525-2531

Gargouri B., Mansour R. B., Abdallah F. B., Elfekih A., Lassoued S., Khaled H. (2011): Protective effect of quercetin against oxidative stress caused by dimethoate in human peripheral blood lymphocytes. Lipids Health Dis. 10, 149

http://dx.doi.org/10.1186/1476-511X-10-149

Gay C., Gebicki J. M. (2000): A critical evaluation of the effect of sorbitol on the ferric-xylenol orange hydroperoxide assay. Anal. Biochem. 284, 217-220 http://dx.doi.org/10.1006/abio.2000.4696

Hatcher H., Planalp R., Cho J., Torti F. M., Torti S. V. (2008): Curcumin: From ancient medicine to current clinical trials. Cell. Mol. Life Sci. 65, 1631-1652 http://dx.doi.org/10.1007/s00018-008-7452-4

Huang J., Zhu M., Tao Y., Wang S., Chen J., Sun W., Li S. (2012): Therapeutic properties of quercetin on monosodium urate crystal-induced inflammation in rat. J. Pharm. Pharmacol. 64, 1119-1127 http://dx.doi.org/10.1111/j.2042-7158.2012.01504.x

Jacobs H., Moalin M., Bast A., van der Vijgh W. J. F., Haenen G. R. (2010): An essential difference between the flavonoids monoHER and quercetin in their interplay with the endogenous antioxidant network. PLoS One 5, e13880

http://dx.doi.org/10.1371/journal.pone.0013880

Ji C., Rouzer C. A., Marnett L. J., Pietenpol J. A. (1998): Induction of cell cycle arrest by the endogenous product of lipid peroxidation, malondialdehyde. Carcinogenesis 19, 1275-1283 http://dx.doi.org/10.1093/carcin/19.7.1275

Jin F., Nieman D. C., Shanely R. A., Knab A. M., Austin M. D., Sha W. (2010): The variable plasma quercetin response to 12-week quercetin supplementation in humans. Eur. J. Clin. Nutr. 64, 692-697 http://dx.doi.org/10.1038/ejcn.2010.91

Kamaraj S., Vinodhkumar R., Anandakumar P., Jagan S., Ramakrishnan G., Devaki T. (2007): The effects of quercetin on antioxidant status and tumor markers in the lung and serum of mice treated with benzo(a)pyrene. Biol. Pharm. Bull. 30, $2268-2273$ http://dx.doi.org/10.1248/bpb.30.2268

Klaunig J. E., Wang Z., Pu X., Zhou S. (2011): Oxidative stress and oxidative damage in chemical carcinogenesis. Toxicol. Appl. Pharmacol. 254, 86-99 http://dx.doi.org/10.1016/j.taap.2009.11.028

Koceva-Chyla A., Gwozdzinski K., Kochman A., Stolarska A., Jozwiak Z. (2003): Effects of pyrroline and pyrrolidine nitroxides on lipid peroxidation in heart tissue of rats treated with doxorubicin. Cell. Mol. Biol. Lett. 8, 179-183 
Koceva-Chyła A., Jędrzejczak M., Skierski J., Kania K., Jóźwiak Z. (2005): Mechanisms of induction of apoptosis by anthraquinone anticancer drugs aclarubicin and mitoxantrone in comparison with doxorubicin: relation to drug cytotoxicity and caspase-3 activation. Apoptosis 10, 1497-1514 http://dx.doi.org/10.1007/s10495-005-1540-9

Kumaraguruparan R., Subapriya R., Kabalimoorthy J., Nagini S. (2002): Antioxidant profile in the circulation of patients with fibroadenoma and adenocarcinoma of the breast. Clin. Biochem. 35, 275-279 http://dx.doi.org/10.1016/S0009-9120(02)00310-7

Lee-Hilz Y. Y., Boerboom A. M., Westphal A. H., Berkel W. J., Aarts J. M., Rietjens I. M. (2006): Pro-oxidant activity of flavonoids induces EpRE-mediated gene expression. Chem. Res. Toxicol. 19, 1499-1505 http://dx.doi.org/10.1021/tx060157q

Leonarduzzi G., Arkan M. C., Basaga H., Chiarpotto E., Sevanian A., Poli G. (2000): Lipid oxidation products in cell signaling. Free Radic. Biol. Med. 28, 1370-1378 http://dx.doi.org/10.1016/S0891-5849(00)00216-1

Levine R. L., Wehr N., Williams J. A., Stadtman E. R., Shacter E. (2000): Determination of carbonyl groups in oxidized proteins. Meth. Mol. Biol. 99, 15-24

Liu W., Kato M., Akhand A. A., Hayakawa A., Suzuki H., Miyata T., Kurokawa K., Hotta Y., Ishikawa N., Nakashima I. (2000): 4-hydroxynonenal induces a cellular redox status-related activation of the caspase cascade for apoptotic cell death. J. Cell Sci. 113, 635-641

Lowry O. H., Rosebrough N. G., Farr A. L., Randall R. J. (1951): Protein measurement with the folin phenol reagent. J. Biol. Chem. 193, 265-275

Mahesh T., Menon V. P. (2004): Quercetin alleviates oxidative stress in streptozotocin-induced diabetic rats. Phytother. Res. 18, 123-127 http://dx.doi.org/10.1002/ptr.1374

Minotti G., Saponiero A., Licata S., Menna P., Calafiore A. M., Teodori G., Gianni L. (2001): Paclitaxel and docetaxel enhance the metabolism of doxorubicin to toxic species in human myocardium. Clin. Cancer Res. 7, 1511-1515

Mir O., Alexandre J., Tran A., Durand J.-P., Pons G., Treluyer J.-M., Goldwasser F. (2009): Relationship between GSTP1 Ile(105)Val polymorphism and docetaxel-induced peripheral neuropathy: clinical evidence of a role of oxidative stress in taxane toxicity. Ann. Oncol. 20, 736-740 http://dx.doi.org/10.1093/annonc/mdn698

Mira L., Fernandez M. T., Santos M., Rocha R., Florêncio M. H., Jennings K. R. (2002): Interactions of flavonoids with iron and copper ions: a mechanism for their antioxidant activity. Free Radic. Res. 36, 1199-1208 http://dx.doi.org/10.1080/1071576021000016463

Misra H., Fridovich I. (1972): The role of superoxide anion in the autooxidation of epinephrine and a simple assay for superoxide dismutase. J. Biol. Chem. 247, 3170-3175

Misset J. L., Dieras V., Gruia G., Bourgeois H., Cvitkovic E., Kalla S., Bozec L., Beuzeboc P., Jasmin C., Aussel J. P., Riva A., Azli N., Pouillart P. (1999): Dose-finding study of docetaxel and doxorubicin in first-line treatment of patients with metastatic breast cancer. Ann. Oncol. 10, 553-560
http://dx.doi.org/10.1023/A:1026418831238

Morse D. L., Gray H., Payne C. M., Gillies R. J. (2005): Docetaxel induces cell death through mitotic catastrophe in human breast cancer cells. Mol. Cancer Ther. 4, 1495-1504 http://dx.doi.org/10.1158/1535-7163.MCT-05-0130

Murakami A., Ashida H., Terao J. (2008): Multitargeted cancer prevention by quercetin. Cancer Lett. 269, 315-325 http://dx.doi.org/10.1016/j.canlet.2008.03.046

Nabholtz J.-M. A. (2003): Docetaxel-anthracycline combinations in metastatic breast cancer. Breast Cancer Res. Treat. 79 (Suppl. 1), S3-9 http://dx.doi.org/10.1023/A:1024369220605

Nam N. H. (2006): Naturally occurring NF-kappaB inhibitors. Mini Rev. Med. Chem. 6, 945-951 http://dx.doi.org/10.2174/138955706777934937

Pandey K. B., Rizvi S. I. (2010): Protection of protein carbonyl formation by quercetin in erythrocytes subjected to oxidative stress. Med. Chem. Res. 19, 186-192 http://dx.doi.org/10.1007/s00044-009-9183-y

Platel D., Pouna P., Bonoron-Ade 'le S., Robert J. (2000): Preclinical evaluation of the cardiotoxicity of taxane-anthracycline combinations using the model of isolated perfused rat heart. Toxicol. Appl. Pharmacol. 163, 135-140 http://dx.doi.org/10.1006/taap.1999.8847

Psotová J., Chlopčíková Š., Miketová P., Hrbáč J., Šimánek V. (2004): Chemoprotective effect of plant phenolics against anthracycline-induced toxicity on rat cardiomyocytes: Part III. Apigenin, baicalelin, kaempherol, luteolin and quercetin. Phytother. Res. 18, 516-521 http://dx.doi.org/10.1002/ptr.1462

Reagan-Shaw S., Nihal M., Ahmad N. (2007): Dose translation from animal to human studies revisited. FASEB J. 22, 659-661 http://dx.doi.org/10.1096/fi.07-9574LSF

Rice-Evans C. A., Diplock A. T., Symons M. C. R. (1991): Techniques in free radical research. In:. Laboratory Techniques in Biochemistry and Molecular Biology. (Eds. R. H. Burdon, P. H. Knippenberg), pp. 147-149, Elsevier, Amsterdam

Rogalska A., Koceva-Chyła A., Jóźwiak Z. (2008): Aclarubicininduced ROS generation and collapse of mitochondrial membrane potential in human cancer cell lines. Chem. Biol. Interact. 176, 58-70 http://dx.doi.org/10.1016/j.cbi.2008.07.002

Rolewski P., Siger A., Nogala-Kałucka M., Polewski K. (2009): Evaluation of antioxidant activity of alpha-tocopherol and quercetin during oxidation of phosphatidylcholine using chemiluminescent detection of lipid hydroperoxides. Pol. J. Food Nutr. Sci. 59, 123-127

Salvatorelli E., Menna P., Cascegna S., Liberi G., Calafiore A. M., Gianni L., Minotti G. (2006): Paclitaxel and docetaxel stimulation of doxorubicinol formation in the human heart: implications for cardiotoxicity of doxorubicin-taxane chemotherapies. J. Pharmacol. Exp. Ther. 318, 424-433 http://dx.doi.org/10.1124/jpet.106.103846

Santin J. C., Deheinzelin D., Junior S. P., Lopes L. F., de Camargo B. (2007): Late echocardiography assessment of systolic and diastolic function of the left ventricle in pediatric cancer survivors after anthracycline therapy. J. Pediatr. Hematol. Oncol. 29, 761-765 http://dx.doi.org/10.1097/MPH.0b013e3181580ea2 
Sawyer D. B., Peng X., Chen B., Pentassuglia L., Lim C. C. (2010): Mechanisms of anthracycline cardiac injury: can we identify strategies for cardioprotection? Prog. Cardiovasc. Dis. 53, 105-113 http://dx.doi.org/10.1016/j.pcad.2010.06.007

Slimestad R., Fossen T., Vågen I. M. (2007): Onions: a source of unique dietary flavonoids. J. Agric. Food Chem. 55, 1006710080 http://dx.doi.org/10.1021/jf0712503

Sokal R. R., Rohlf F. J. (1994): Biometry: The principles and practice of statistics in biological research (3rd edition). (Ed. W. H. Freeman), pp. 272-308, New York

Steffen Y., Gruber C., Schewe T., Sies H. (2008): Mono-O-methylated flavanols and other flavonoids as inhibitors of endothelial NADPH oxidase. Arch. Biochem. Biophys. 469, 209-219 http://dx.doi.org/10.1016/j.abb.2007.10.012

Yamaguchi T., Takamura H., Matoba T., Terao J. (1998): HPLC method for evaluation of the free radical-scavenging activity of foods by using 1,1-diphenyl-2-picrylhydrazyl. Biosci. Biotechnol. Biochem. 62, 1201-1204 http://dx.doi.org/10.1271/bbb.62.1201

Yang Y., Sharma R., Sharma A., Awasthi S., Awasthi Y. C. (2003): Lipid peroxidation and cell cycle signaling: 4-hydroxynonenal, a key molecule in stress mediated signaling. Acta Biochim. Pol. 50, 319-336

Zar J. H. (1999): Biostatistical analysis (4th edition). pp. 303-311, Prentice Hall, Upper Saddle River, NJ

Zelenka J., Muchova L., Zelenkova M., Vanova K., Vreman H. J., Wong R. J., Vitek L. (2012): Intracellular accumulation of bilirubin as a defense mechanism against increased oxidative stress. Biochimie 94, 1821-1827

http://dx.doi.org/10.1016/j.biochi.2012.04.026

Received: January 31, 2013

Final version accepted: April 26, 2013 